researcher Robert Lefkowitz's chemistry Nobel — two Korean scientists, Jihee Kim and Seungkirl Ahn, are currently working in his lab.

And although Japan's Shinya Yamanaka was personally congratulated by Prime Minister Yoshihiko Noda on his award in physiology or medicine, the San Jose Mercury News preferred to focus on Yamanaka's training at the Gladstone Institutes in San Francisco, California, which, the paper said, recognized his talents back in 1993 , when they hired him (Yamanaka still has a lab there).

Reactions such as these show how national pride and prestige still matter in an increasingly internationalized science system. The ultimate expression of that tension will surely come when the discovery of the Higgs boson - to which thousands of researchers and funds from tens of countries contributed - is rewarded with a call from Stockholm.

This week, Nature examines the globalization of science (see page 325). According to the US National Science Foundation (NSF), almost one-quarter of research articles in 2010 featured authors from more than one country, up from $10 \%$ in 1990 . The average number of authors on research papers, which now stands at 4.5 , has doubled since 1980. Many areas of science are becoming international, not local, pursuits; researchers are increasingly criss-crossing the globe and becoming accustomed to working in two or three countries at once.

Yet although science is increasingly globalized - at least in terms of research outputs and collaborations - it is still funded and managed on a largely national basis. This may need to change. Joining up national priorities could allow economies of scale, possibly to the benefit of research into global challenges such as energy, climate and agriculture.
The head of the NSF, Subra Suresh, offers a vision of the future on page 337 in which some of the barriers to cross-border scientific collaboration have been removed. Suresh hopes that the Global Research Council can begin to collectively steward global science as if it were a national activity.

If the globalizing trend does continue, it could change the way that national governments view the outputs of science. Countries may even
"Joining upnational priorities could allow economies of scale." feel that, instead of insisting on making and exploiting their own discoveries, it is more efficient to capitalize on the breakthroughs made by others. South Korea and the United States are rapidly becoming the centres of graphene manufacturing, for instance, despite the 2010 physics Nobel being awarded to graphene researchers at the University of Manchester, UK.

Yet there are limits to internationalization. Mobility cannot stretch infinitely: relationships, families and quality of life put limits on how much researchers want to travel, and for how long. Meanwhile, some national research systems, such as that of Japan, are not particularly flexible and discourage scientists from spending too much time abroad.

And blurring the borders of national priorities may not be all good. Some countries are just beginning to build their own research capacity. Collaboration may allow them to share in the advances of others, but it could also start to dilute their national identity, subjugating local research priorities to the interests of larger nations. Striking the balance between local and global science will be the challenge.

\section{Badger away}

\section{Charges that the UK badger-shooting policy ignores evidence are wide of the mark.}

\section{$\mathrm{I}$} n England's meadows, a massacre is imminent. As Nature went to press, licensed marksmen were getting ready to take aim at badgers - a native species that is a known carrier of bovine tuberculosis (TB). By the time you read this, the first shots in a long and bloody conflict may have been fired.

Scientists are outraged. Many researchers insist that the government has ignored the data in favour of a policy to appease farmers. But the evidence suggests something else: politicians have reviewed the science and have responded to it. The resulting policy is far from what many scientists would have hoped, but it is nevertheless based on evidence.

As described on page 317, the badger question is one of the moststudied environmental problems in modern Britain. At issue is the degree to which badgers (Meles meles) contribute to the spread of bovine TB - an economically costly disease - and whether killing them can help to control it. Decades of study have led to a clear scientific answer of "a fair bit" to the first question and "maybe" to the second.

More specifically, an extensive, randomized study showed a roughly $23 \%$ reduction in bovine TB over a 9 -year period of badger culling in small areas. The same study, however, concluded that catching the badgers in cages and shooting them was unlikely to be economically practical and therefore advised against it.

On the basis of that evidence, the previous, Labour government decided not to instigate a badger cull. The present Conservative-led government sees things differently. With a cheaper cull strategy that relies on free shooting instead of traps, the government believes badger culling might help to reduce bovine TB, which has been rising steadily.

Scientists have not been excluded from this decision. In April 2011, the Department for Environment, Food and Rural Affairs convened a panel of scientists to review the evidence and advise on whether a cull could work. The scientists, including several who now actively oppose the government's policy, gave a qualified 'yes'. Culling could reduce bovine TB by perhaps $16 \%$ over 9 years, the scientists said, but it would be difficult to know if free shooting would work because it differed from the method tested in the previous trial.

Partly on the basis of that analysis, the government seems to think that it's worth a shot. In combination with other techniques, such as increased monitoring and controls on cattle movements, it hopes that the badger cull can bring bovine TB under control. The politicians accept the modest reduction that scientists say the cull may bring, and have adopted scientific recommendations for how best to implement it, such as using rivers and roads as boundaries for their cull areas and setting a 70\% target for the number of badgers killed (although knowing when this target has been reached will be difficult, because there has been no census of badger populations).

Scientists protest that this decision is still unscientific, because the methods to be used are too different from those of the original trial and because the evidence suggests that they may not work. There is a chance that the cull will have little impact or could even increase the TB rate if improperly conducted.

But it is the government's job to create and implement policy, not to perform science experiments. Politicians must make decisions every day with imperfect knowledge, knowing that many of those choices may turn out to be ineffective. In this case, they feel a need to do something to bring bovine TB under control - or at least to be seen to be trying to do so. They also face considerable pressure from unhappy farmers who are being told to implement costly biosecurity measures while badgers run free.

Politicians all too frequently ignore scientific evidence, or worse still, distort it for their own purposes. The political debates over genetically modified food in Europe and climate change in the United States in recent years hold many examples of such behaviour. The badger issue is more nuanced. Politicians have understood the evidence, have $\rightarrow$ NATURE.COM To comment online, click on Editorials at: go.nature.com/xhunqv acknowledged this evidence publicly and have made a policy that partially reflects it. Scientists have every right to disagree with the conclusion, but they should reconsider their criticisms of how it was reached. 